\title{
The severity of cognitive deficits predicts return to work after a first-ever ischaemic stroke
}

\author{
Tatu Kauranen, ${ }^{1,2}$ Katri Turunen, ${ }^{1,3}$ Siiri Laari, ${ }^{1,3}$ Satu Mustanoja, ${ }^{3}$ Peter Baumann, ${ }^{2}$ \\ Erja Poutiainen ${ }^{1,3}$
}

- Additional materials are published online only. To view these files please visit the journal online (http://dx.doi.org/ 10.1136/jnnp-2012-302629).

${ }^{1}$ University of Helsinki, Institute of Behavioral Sciences, Helsinki, Finland

${ }^{2}$ Department of Neurology and Clinical Neurophysiology, Lapland Central Hospital, Rovaniemi, Finland

${ }^{3}$ Helsinki University Central Hospital, Helsinki, Finland

\section{Correspondence to}

Tatu Kauranen, Department of Neurology, Lapland Central Hospital, P.0. Box 8041, FIN-96200 Rovaniemi, Helsinki, Finland; tatu.kauranen@Ishp.fi

Received 28 February 2012 Revised 19 June 2012 Accepted 2 August 2012

Published Online First

5 September 2012

\section{SLinked}

- http://dx.doi.org/10.1136/ jnnp-2012-303328

- http://dx.doi.org/10.1136/ jnnp-2013-304886

\begin{abstract}
Background The inability of stroke patients to return to work contributes disproportionately to the socioeconomic impact of stroke and is best predicted by the severity of stroke. However, the role of cognitive deficits in stroke severity has not been scrutinised. We studied whether the initial cognitive severity of stroke, compared with other influential factors, predicts the inability to return to work after stroke.
\end{abstract}

Methods Consecutive patients aged 18-65 with a firstever ischaemic stroke, working full time previously, were assessed neuropsychologically within the first weeks after stroke and at the 6-month follow-up. Similarly, 50 healthy demographic controls were assessed twice. The cognitive severity of stroke was operationalised as the number of initial cognitive deficits. Cognitive severity as a predictor of the inability to return to work was compared with demographic, occupational, neurological, radiological and functional data, vascular risk factors and mood state.

Results The mean age of the 140 patients assessed both initially and at follow-up was 52 years. They had a mean of 13 years of education and $59 \%$ were men. At 6 months, only $41 \%$ of the patients had returned to work despite the relatively minor neurological and functional impairments of the cohort. In our model, the number of early cognitive deficits $(\mathrm{OR}=2.252, \mathrm{Cl} 1.294$ to 3.918$)$ was the only significant predictor of the inability to return to work.

Conclusions The initial cognitive severity of stroke predicts the later inability to return to work. The benefits of neuropsychological assessments within the first weeks after stroke are emphasised.

\section{INTRODUCTION}

The productivity losses of young stroke survivors not returning to work contribute disproportionately to the socioeconomic impact of stroke. ${ }^{1}$ Stroke severity is a known predictor of return to work, ${ }^{23}$ but in different studies the severity refers to different aspects of the patient data. Usually the severity is defined as gross neurological and functional impairment. Neurological impairment is often measured with the National Institutes of Health Stroke Scale (NIHSS), ${ }^{4} 5$ and functional status with the Barthel Index. ${ }^{5-8}$ In addition to neurological and functional impairment, the severity of stroke refers to cognitive disturbances. ${ }^{2}$ Specific cognitive deficits seem to be negatively associated with return to work, ${ }^{9}$ but the evidence remains inconclusive. In general, the data on cognition are restricted to single severe deficits such as aphasia, which are already detected in the NIHSS. More subtle cognitive disturbances are usually disregarded because studies on return to work and cognition often lack detailed neuropsychological assessments. ${ }^{5} 710-13$ We found one study with a thorough neuropsychological assessment at 3 months after stroke, reporting that the defects of intelligence and memory affected the return to work. ${ }^{14}$ Although earlier domain-specific cognitive abilities, found within the first weeks after stroke, are excellent independent predictors of long-term cognitive, ${ }^{15}$ and functional, ${ }^{16}{ }^{17}$ outcome and quality of life, ${ }^{18} 19$ their role in predicting return to work remains unexplored.

An analysis of the occupational outcome after stroke needs to be adjusted for several influential factors, including demographics and occupational status. For example, blue-collar workers are less likely to return to work than white-collar workers, and older patients close to their pension have a poorer return to work rate than younger stroke survivors. $^{2} 1020$ Furthermore, the definitions of work significantly affect the results in return to work studies. ${ }^{2}$ Trying to unify the concepts, studies defining work as employment, often outside the house, are increasing. For example, in a recent review on the social consequences of stroke, ${ }^{3} 51$ of 78 studies had defined return to work as full- or part-time employment.

Our aim was to investigate how the severity of stroke, defined as the number of cognitive deficits within the first weeks after a first-ever ischaemic stroke, predicts the inability to return to employment after 6 months. The analysis was adjusted for demographic, occupational and clinical predictors and mood state. Given that gross cognitive impairments are known to predict return to work, we hypothesised that a more sensitive assessment of cognitive deficits would enhance these predictions.

\section{METHODS \\ Subjects}

The patient data are part of a prospective cohort study focusing on neuropsychological factors related to ischaemic stroke. The data were collected consecutively in two Finnish hospitals: Helsinki University Central Hospital and Lapland Central Hospital during April 2007-October 2009. Informed consent was gathered from all participants. The patients were treated according to normal clinical standards for stroke patients. The inclusion criteria were a first-ever diagnosed 
supratentorial ischaemic stroke, aged 18-65years, with no relevant neurological, psychiatric or neuropsychiatric history or comorbidity, and being a native Finnish speaker. The controls met all inclusion criteria except the stroke. The study and consent procedure were accepted by the ethics committee of Helsinki University Central Hospital in accordance with institutional guidelines. In addition, only patients working outside the house in full-time paid employment before the stroke were included.

\section{Clinical data}

The NIHSS and Glasgow Coma Scale (GCS) ${ }^{21}$ were completed for all the patients twice: at their admittance to hospital and at discharge from the acute care unit. The pathophysiological aetiologies of the infarcts were categorised according to the Trial of Org 10172 in acute stroke treatment criteria. ${ }^{22}$ An experienced stroke neurologist visually evaluated the lesion location and size and the side of the infarction from CT or MRI (taken during the acute phase). The locations were categorised as frontal, parietal, temporal, occipital, basal ganglia, multiple with more than one location or non-visible. The infarct size was categorised using a modified version of Paciaroni et $\mathrm{al}^{23}$ as small $(<1.5 \mathrm{~cm})$, medium $(1.5-4.0 \mathrm{~cm})$ or large $(>4.0 \mathrm{~cm})$. The basic functional status was assessed with the Barthel Index at the time of the initial neuropsychological assessment. The data on the principal vascular risk factors, that is, atrial fibrillation, diabetes, hypercholesterolaemia, hypertension, overweight (Body Mass Index >25) and smoking, were collected from the medical reports. The accumulation sum score of the vascular risk factors was used in the analysis.

\section{Neuropsychological assessments and mood state}

Every consecutive patient eligible based on the inclusion criteria completed the neuropsychological assessment according to the study protocol after a neurologist determined that the patient's condition had stabilised. The neuropsychological assessment was repeated after 6 months to validate the outcome predictions made with the initial neuropsychological assessment. Similarly, the controls were assessed twice, in 3-month intervals. The patients' follow-up assessments were compared with those of the controls.

In the neuropsychological assessments, we evaluated deficits in seven cognitive functions: executive functions, psychomotor speed, episodic memory, working memory, language, visual spatial and constructional skills, and motor skills (see online supplementary table 1). We measured each of the seven cognitive functions with three different neuropsychological tests. $^{24-34}$ The inner consistency (Cronbach's $\alpha$ ) of the neuropsychological test scores within each cognitive function ranged from 0.74 to 0.93 . Mimicking clinical decision-making, we required more than one test to deviate to denote impairment. A deficit in a cognitive function was recorded as present, when at least two test scores out of the three measuring the same function were considered defective. The cut-off for a defective performance in a test score was set to the tenth percentile level of the control group's performance. A similar method of defining cognitive deficits has been used previously. ${ }^{35}$ The cognitive severity of stroke was defined as the number of initial cognitive deficits.

The follow-up neuropsychological data were binary encoded as the persistence of cognitive deficits to avoid excess multicollinearity of the predictors. Persistence refers to a situation in which there was no improvement at follow-up in any of the initially defective test performances contributing to an early cognitive deficit. In addition, persistence was encoded in those cases for which a new defective test performance within an early cognitive deficit was found and for which a new cognitive deficit was found at the follow-up. Non-persistence refers to a followup performance, in which at least one of the initially defective test performances contributing to an early cognitive deficit was no longer defective at the later follow-up. Additionally, nonpersistence was encoded in cases with non-existent early cognitive deficit and no new deficits at the follow-up.

The mood state of the patients was evaluated at both neuropsychological assessments using a modified version of the Profile of Mood States (POMS) questionnaire. ${ }^{36}$ POMS includes questions concerning mood, apathy and fatigue. In the analyses, the 90th percentile level of the control group's symptom sum score was used as the cut-off for an impaired mood state.

\section{Occupational data}

The occupational status and type of work were collected in a clinical interview as a part of the initial neuropsychological assessment. At the 6-month follow-up, the patients' occupational statuses were recollected with a questionnaire modified from that of Sheehan et al. ${ }^{37}$ The main dependent variable, the inability to return to work, was defined as not returning to paid employment outside the house, either full or part time. If a patient was on a sick leave or disability pension at follow-up, the diagnosis was confirmed from the related medical certificate. The type of work was classified as managerial employee, clerical employee, employee, entrepreneur or student. A managerial employee refers to occupations typically requiring an academic degree, often but not always a managerial position with several subordinates, for example, medical doctors and chief executive officers. A clerical employee designates occupations that require a vocational degree below the academic degree, including many types of office workers, for example, secretary and book-keeper. An employee indicated manual labour, for example, construction worker and housekeeper. An entrepreneur designates practitioners, freelancers, professional workers and self-employed persons. A student refers to full-time students, for example, in vocational studies.

\section{Statistical analyses}

The statistical analyses were computed with the IBM SPSS Statistics V.20.0. The univariate associations of all the predictors with the inability to return to work were analysed. Those predictors with a significant univariate association were chosen for the subsequent multivariate analysis. An enter-method binary logistic regression model was created to compare the significant predictors of the inability to return to work.

\section{RESULTS}

\section{Sample characteristics}

The criterion of working full time outside the house prior to the stroke was fulfilled in 161 of the 230 patients and, of those, 140 (final number of patients) completed the follow-up assessment and were analysed. The thorough sampling of this study is illustrated in figure 1. In the sample, there were 83 men $(59.3 \%)$. The mean age of our patients was 52.0 years $(\mathrm{SD}=10.5)$ and they had a mean of 12.5 years $(S D=2.6)$ of education. The distributions of sex, age, education, type of work and accumulation of vascular risk factors did not differ between the patient $(\mathrm{n}=140)$ and control $(\mathrm{n}=50)$ groups (table 1$)$.

The dropouts $(n=21)$ from the 6-month follow-up assessment had higher NIHSS scores than the included patients (admittance: dropouts median $=5$, included patients median $=2$, 


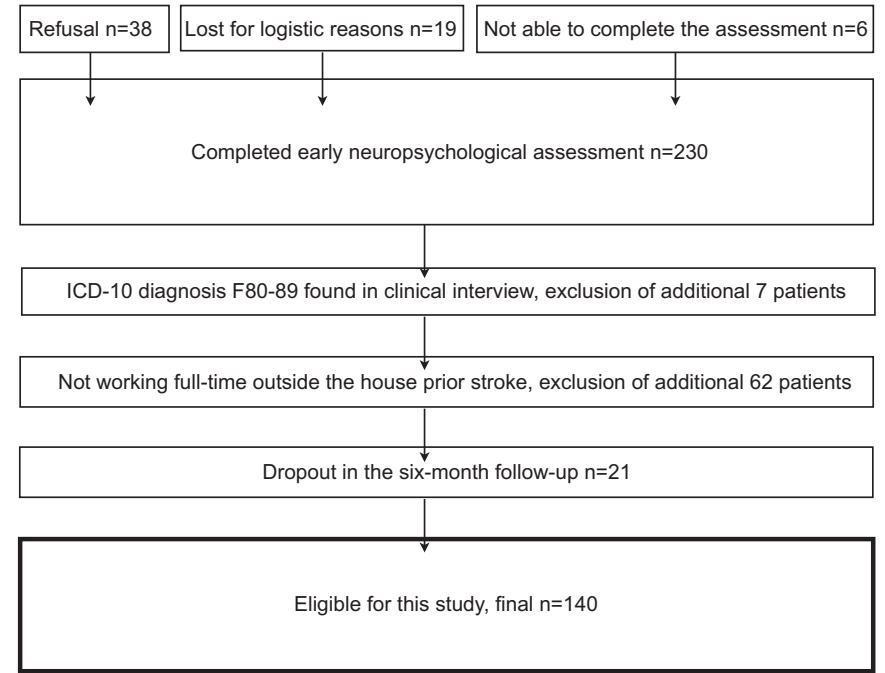

Figure 1 Sample characteristics. ICD-10, the 10th revision of the International Statistical Classification of Diseases and Related Health Problems.

$\mathrm{U}=909.500, \mathrm{p}<0.01$; discharge: dropouts median $=2$, included patients median $=1, U=1047.500, p<0.05)$. Additionally, the dropouts had a deficit in psychomotor speed significantly more often than the included patients (dropouts 12/21 (57.1\%), included patients $43 / 140$ (30.7\%), $\left.\chi^{2}(1)=5.671, p<0.05\right)$. No significant differences were found between the dropouts and the included patients in any other demographic, occupational, clinical, cognitive or mood state measurements.

\section{Clinical characteristics}

The neurological, radiological and functional characteristics of the patient cohort and the vascular risk factors are presented in

Table 1 Demographic, occupational and vascular risk factor characteristics

\begin{tabular}{llll}
\hline & $\begin{array}{l}\text { Stroke } \\
\text { patients } \\
\mathbf{N}=\mathbf{1 4 0}\end{array}$ & $\begin{array}{l}\text { Controls } \\
\mathbf{N}=\mathbf{5 0}\end{array}$ & $\begin{array}{l}\text { Patients } \\
\text { versus } \\
\text { controls }\end{array}$ \\
\hline Men/women, N (\%) & $83(59.3) / 57$ & $31(62.0) / 19$ & $\mathrm{p}=0.737^{*}$ \\
& $(40.7)$ & $(38.0)$ & \\
Age, mean (SD) & $52.0(10.5)$ & $54.3(9.0)$ & $\mathrm{p}=0.161 \dagger$ \\
Education years, mean (SD) & $12.5(2.6)$ & $12.4(2.9)$ & $\mathrm{p}=0.814 \dagger$ \\
Type of work & & & $\mathrm{p}=0.518^{*}$ \\
Managerial employee, N (\%) & $37(26.4)$ & $16(32.0)$ & \\
Clerical employee, N (\%) & $26(18.6)$ & $11(22.0)$ & \\
Employee, N (\%) & $61(43.6)$ & $21(42.0)$ & \\
Entrepreneur, N (\%) & $11(7.9)$ & $2(4.0)$ & \\
Student, N (\%) & $5(3.6)$ & $0(0.0)$ & \\
Accumulation of vascular risk factors & & & $\mathrm{p}=0.067 \neq$ \\
Atrial fibrillation, N (\%) & $16(11.4)$ & $1(2.0)$ & \\
Diabetes, N (\%) & $14(10.1)$ & $3(6.0)$ & \\
Hypercholesterolaemia, N (\%) & $80(57.1)$ & $29(58.0)$ & \\
Hypertension, N (\%) & $88(62.9)$ & $29(58.0)$ & \\
Overweight, N (\%) & $90(64.3)$ & $35(70.0)$ & \\
Smoking, N (\%) & $50(35.7)$ & $9(18.0)$ & \\
\hline
\end{tabular}

\section{${ }^{*} \chi^{2}$ Statistics.}

tt Statistics

¥U Statistics; managerial employee: occupations typically requiring an academic degree; clerical employee: occupations requiring a vocational degree below the academic degree; employee: manual labour; entrepreneur: for example, practitioners and self-employed persons; student: full-time students; accumulation of vascular risk factors: sum score of vascular risk factors.
Table 2 Baseline clinical characteristics of the stroke patients

\begin{tabular}{lc}
\hline & $\mathbf{N}=140$ \\
\hline National Institute of Health Stroke Scale & \\
Admittance to hospital, median (min-max) & $2(0-24)$ \\
Discharge from the acute care unit, median (min-max) & $1(0-13)$ \\
Glasgow Coma Scale & \\
Admittance to hospital, median (min-max) & $15(10-15)$ \\
Discharge from the acute care unit, median (min-max) & $15(10-15)$ \\
Aetiology by TOAST & \\
Large-artery atherosclerosis, N (\%) & $36(25.7)$ \\
Cardioembolism, N (\%) & $31(22.1)$ \\
Small-artery occlusion, N (\%) & $29(20.7)$ \\
Other determined, N (\%) & $15(10.7)$ \\
Undetermined, N (\%) & $29(20.7)$ \\
Lesion location & \\
Frontal, N (\%) & $6(4.3)$ \\
Parietal, N (\%) & $8(5.7)$ \\
Temporal, N (\%) & $7(5.0)$ \\
Occipital, N (\%) & $10(7.1)$ \\
Basal ganglia, N (\%) & $37(26.4)$ \\
More than one location, N (\%) & $42(30.0)$ \\
Lesion size & \\
$<1.5 \mathrm{~cm}, \mathrm{~N}(\%)$ & $58(41.4)$ \\
1.5-4.0 cm, N (\%) & $29(20.7)$ \\
$>4.0 \mathrm{~cm}, \mathrm{~N}(\%)$ & $23(16.4)$ \\
Lesion side & \\
Left, N (\%) & $53(21.7)$ \\
Right, N (\%) & $100(25-100)$ \\
Bilateral, N (\%) & \\
Lesion not visible, N (\%) & \\
Barthel Index, median (min-max) & \\
\hline TOAST, Trial of Org 10172 in acute stroke treatment. & \\
& \\
&
\end{tabular}

table 2. At hospital admission, 122 patients (87.1\%) had gross neurological findings with an NIHSS score above 0 . At the discharge from the acute care unit, 91 patients (65.0\%) still had an NIHSS score of 1 or more. Large-artery atherosclerosis was the dominant pathophysiological aetiology ( $n=36,25.7 \%$ ) of the infarcts. Hypertension ( $n=87,62.1 \%$ ) and hypercholesterolaemia ( $n=79,56.4 \%$ ) were the most frequent vascular risk factors in our cohort.

\section{Cognitive and mood state characteristics}

The first neuropsychological assessment was completed after a mean of 8 days (SD 4.5) poststroke. At the 6-month follow-up assessment, the mean delay was 186 days (SD 14.9). The prevalences of the cognitive deficits at both assessments are given in online supplementary figure 1 . At the initial assessment, 75 patients $(53.6 \%)$ had at least one cognitive deficit, and at the 6-month follow-up, 59 patients (42.1\%) had at least one deficit. Deficits in executive functions and psychomotor speed were the most prevalent deficits at both initial and follow-up assessments. All the differences in prevalence between the assessments were significant at $p<0.001$ in $\chi^{2}$ statistics (the number of cognitive deficits was analysed as a four category $(0,1,2, \geq 3$ deficits) sum score). An impaired mood state was found in 45 patients $(31.8 \%)$ at the initial assessment and in 25 patients $(18.1 \%)$ at follow-up.

\section{Occupational characteristics}

The distribution of the types of work in the patient cohort and control groups are presented in table 1. The patients' 
occupational statuses at the 6-month follow-up categorised by the type of work are illustrated in online supplementary figure 2. By 6 months after the stroke, 58 patients (41.4\%) had succeeded in returning to work, 65 patients (46.4\%) were still on sick leave and four patients $(2.9 \%)$ were on a disability pension. Stroke was traced as the cause of the sick leave and disability pension in all but one case. In that particular case, a coincidental new diagnosis of bipolar disorder caused the uncertainty.

\section{One-way associations with the inability to return to work}

The one-way associations among demographic, occupational, clinical, cognitive and mood state factors and the inability to

Table 3 Associations among the inability to return to work 6 months after a first-ever ischaemic stroke and the demographic, occupational, clinical and cognitive factors and mood state

\begin{tabular}{|c|c|c|}
\hline & Value (df) & p Value \\
\hline \multicolumn{3}{|l|}{ Demographic data } \\
\hline Sex & $0.234(1)^{*}$ & 0.628 \\
\hline Age & $-3.252(138) \dagger$ & 0.001 \\
\hline Education & $2.149(138) \dagger$ & 0.033 \\
\hline Occupational data: type of work & $8.674(4)^{*}$ & 0.070 \\
\hline Accumulation of vascular risk factors & $655.500 \neq$ & 0.379 \\
\hline \multicolumn{3}{|l|}{ Neurological data } \\
\hline \multicolumn{3}{|l|}{ National Institute of Health Stroke Scale } \\
\hline Admittance & $1475.500 \ddagger$ & 0.000 \\
\hline Discharge & $1155.500 \neq$ & 0.000 \\
\hline \multicolumn{3}{|l|}{ Glasgow Coma Scale } \\
\hline Admittance & $1874.000 \ddagger$ & 0.003 \\
\hline Discharge & $2088.000 \ddagger$ & 0.006 \\
\hline Aetiology by TOAST & $12.198(4)^{*}$ & 0.016 \\
\hline \multicolumn{3}{|l|}{ Radiological data } \\
\hline Lesion location & $10.823(8)^{*}$ & 0.212 \\
\hline Lesion size & $11.722(3)^{*}$ & 0.008 \\
\hline Lesion side & $2.816(3)^{*}$ & 0.421 \\
\hline Functional data: Barthel Index & $1607.000 \neq$ & 0.000 \\
\hline \multicolumn{3}{|l|}{ Neuropsychological data: early assessment } \\
\hline Number of cognitive deficits & $1038.500 \ddagger$ & 0.000 \\
\hline \multicolumn{3}{|l|}{ Cognitive deficit in } \\
\hline Executive functions & $23.011(1)^{*}$ & 0.000 \\
\hline Psychomotor speed & $19.307(1)^{*}$ & 0.000 \\
\hline Episodic memory & $17.564(1)^{*}$ & 0.000 \\
\hline Working memory & $9.990(1)^{*}$ & 0.002 \\
\hline Language & $15.595(1)^{*}$ & 0.000 \\
\hline Visual spatial and constructional skills & $17.564(1)^{*}$ & 0.000 \\
\hline Motor skills & $16.284(1)^{*}$ & 0.000 \\
\hline \multicolumn{3}{|l|}{ Neuropsychological data: follow-up } \\
\hline Number of cognitive deficits & $1372.000 \neq$ & 0.000 \\
\hline Persistence of deficits & $16.842(1)^{*}$ & 0.000 \\
\hline \multicolumn{3}{|l|}{ Cognitive deficit in } \\
\hline Executive functioning & $8.818(1)^{*}$ & 0.003 \\
\hline Psychomotor speed & $16.542(1)^{*}$ & 0.000 \\
\hline Episodic memory & $10.954(1)^{*}$ & 0.001 \\
\hline Working memory & $9.213(1)^{*}$ & 0.002 \\
\hline Language & $9.284(1)^{*}$ & 0.002 \\
\hline Visual spatial and constructional skills & $0.671(1)^{*}$ & 0.413 \\
\hline Motor skills & $5.759(1)^{*}$ & 0.016 \\
\hline \multicolumn{3}{|l|}{ Mood state: profile of mood states } \\
\hline Early assessment & $1.400(1)^{*}$ & 0.237 \\
\hline Follow-up & $1.678(1)^{*}$ & 0.195 \\
\hline
\end{tabular}

return to work are presented in table 3. Age $(p<0.01)$ and education $(p<0.05)$, but not sex, were related to the inability to return to work. The type of work was associated with the outcome but did not reach significance $(p=0.07)$.

The NIHSS (admittance: $p<0.001$, discharge: $p<0.001$ ) and GCS scores (admittance: $p<0.01$, discharge: $p<0.01$ ) and the stroke aetiology (Trial of Org 10172 in acute stroke treatment) $(\mathrm{p}<0.05)$ were associated with the inability to return to work. In total, $72.2 \% \quad(n=26 / 36)$ of the patients in the large artery atherosclerosis group, $71.0 \%(n=22 / 31)$ in the cardioembolism group and $66.7 \%(n=10 / 15)$ in the other determined cause group were unable to return to work. In contrast, $41.4 \%$ ( $n=12 / 29)$ of the patients with either small-artery occlusion or undetermined cause did not return to work. The size of the lesion $(p<0.01)$ as the only significant radiological factor and the functional Barthel Index $(p<0.001)$ also had a significant one-way association with the outcome.

Every initial cognitive deficit associated with the outcome. At the 6-month follow-up, all but the visual spatial and constructional skills had a significant one-way association with the inability to return to work. In contrast, mood state was not associated with the outcome in either measurement.

\section{The multivariate model of the inability to return to work}

The model of the inability to return to work including every variable with a significant one-way association with the outcome is presented in table 4. For the gross neurological measures, only the measurement with a stronger univariate association (NIHSS: discharge, GCS: admittance) was selected for the final model to eliminate excess multicollinearity. In addition to variables with significant associations, type of work, which had a nearly significant association, was included. The early neuropsychological assessment was included in the model as the number of initial cognitive deficits. The neuropsychological follow-up assessment was included in the model as the persistence of cognitive deficits. Otherwise, all the variables with a significant univariate association with the outcome were included. In the model, only the number of initial cognitive deficits $(O R=2.251,95 \%$ CI 1.294 to 3.918, $p<0.01)$ was a significant predictor. Compared with a patient with no initial cognitive deficits, every cognitive deficit a patient had doubled the risk of the inability to return to work. The persistence of initial cognitive deficits was the only other predictor that came close to reaching the level of significance $(\mathrm{OR}=2.722,95 \% \mathrm{CI}$ 0.942 to $7.861, \mathrm{p}=0.06$ ).

\section{DISCUSSION}

In our study, the cognitive severity of stroke within the first weeks predicted the inability to return to work 6 months after a stroke. In our analysis, we accounted for demographic, occupational and clinical predictors as well as mood state. Impairments in psychomotor speed and executive functions were the most prevalent cognitive deficits. Stroke patients seem to benefit from early neuropsychological assessments after stroke for the evaluation of their rehabilitation needs and for the prediction of occupational outcome. This finding is a valuable addition to previous research, which has emphasised cognitive impairments as predictors of the cognitive, ${ }^{15}$ and functional, ${ }^{16}{ }^{17}$ outcomes and quality of life $e^{18} 19$ after stroke.

In this cohort, $41 \%$ of the patients previously working full time in paid employment outside the house had returned to work 6 months after the infarct. The poststroke return to work rates vary noticeably among different studies due to different definitions of work. ${ }^{2}{ }^{3}$ Studies defining work the same way we 
Table 4 Logistic regression model of the inability to return to work 6 months after a first-ever ischaemic stroke

\begin{tabular}{|c|c|c|c|c|c|}
\hline \multirow[b]{2}{*}{ Predictor } & \multirow[b]{2}{*}{ Wald (df) } & \multirow[b]{2}{*}{ p Value } & \multirow[b]{2}{*}{$\mathbf{O R}$} & \multicolumn{2}{|l|}{$95 \% \mathrm{Cl}$} \\
\hline & & & & Lower & Upper \\
\hline Number of cognitive deficits* & $8.240(1)$ & 0.004 & 2.251 & 1.294 & 3.918 \\
\hline Persistence of the deficits $†$ & $3.423(1)$ & 0.064 & 2.722 & 0.942 & 7.861 \\
\hline Age & $1.195(1)$ & 0.274 & 1.036 & 0.972 & 1.105 \\
\hline Education years & $0.000(1)$ & 0.993 & 1.001 & 0.787 & 1.273 \\
\hline Type of work & $1.140(4)$ & 0.888 & & & \\
\hline Clerical employee & $0.441(1)$ & 0.507 & 0.569 & 0.108 & 3.001 \\
\hline Employee & $0.026(1)$ & 0.871 & 0.886 & 0.204 & 3.848 \\
\hline Entrepreneur & $0.496(1)$ & 0.481 & 0.484 & 0.064 & 3.647 \\
\hline Student & $0.303(1)$ & 0.582 & 0.402 & 0.016 & 10.288 \\
\hline National Institute of Health Stroke Scale§ & $2.558(1)$ & 0.110 & 1.532 & 0.908 & 2.582 \\
\hline Glasgow Coma Scale $\ddagger$ & $1.408(1)$ & 0.235 & 0.754 & 0.473 & 1.202 \\
\hline Aetiology by TOAST & $3.123(4)$ & 0.537 & & & \\
\hline Cardioembolism & $0.175(1)$ & 0.676 & 0.736 & 0.175 & 3.092 \\
\hline Small-artery occlusion & $1.789(1)$ & 0.181 & 0.383 & 0.094 & 1.563 \\
\hline Other determined & $0.148(1)$ & 0.701 & 1.490 & 0.195 & 11.416 \\
\hline Undetermined & $1.051(1)$ & 0.305 & 0.473 & 0.113 & 1.980 \\
\hline Lesion size & $0.005(1)$ & 0.943 & 0.979 & 0.554 & 1.732 \\
\hline Barthel Index* & $2.121(1)$ & 0.145 & 0.923 & 0.829 & 1.028 \\
\hline Constant & $1.992(1)$ & 0.158 & 11747.111 & & \\
\hline
\end{tabular}

*After a mean of 8 days after the onset.

†Persistence=no improvement at 6-month follow-up

$\ddagger$ At admittance to hospital: the inability to return to work is the predicted category. The reference category for the type of work is managerial employee. The reference category for aetiology is large-artery atherosclerosis. Managerial employee: occupations typically requiring an academic degree; clerical employee: occupations requiring a vocational degree below the academic degree; employee: manual labour; entrepreneur: for example, practitioners and self-employed persons; student: full-time students.

$\S$ At discharge from the acute care unit.

TOAST, Trial of Org 10172 in acute stroke treatment.

did—as paid employment outside the house-typically report approximately half of the patients returning to work. ${ }^{3}$ Our slightly lower rate could possibly reflect differences, for example, in the loss of income grants between the involved countries.

The prevalence of having any cognitive deficit in the first weeks after stroke is found to be above $70 \%$, and within the first 3 months $50 \%-90 \%{ }^{38}$ Found prevalences depend on the sampling, the timing of the assessments and the definition of a cognitive deficit in the different studies. In our fairly young stroke cohort, we defined cognitive deficits by mimicking clinical decision-making, resulting in prevalences of $54 \%$ within the first weeks and $42 \%$ at the 6-month follow-up. Deficits in executive functions and psychomotor speed were the most prevalent cognitive deficits at both the initial and 6-month follow-up assessment.

The association of the severity of stroke with the occupational outcome was clear in our data for the NIHSS and for the functional Barthel Index in conjunction with previous studies. ${ }^{5}$ Our data also replicate previous research for other factors affecting the occupational outcome after stroke, such as age, education and type of work. ${ }^{10}{ }^{20}$ What is new in our study is that an adjustment of the analysis of these diverse factors for the effect of cognitive disturbances led to the proposal that the cognitive severity of stroke was an even more important predictor.

However, the low median NIHSS scores indicate a need to evaluate the generalisability of our patient cohort. Furthermore, the physically mild nature of the cohort is highlighted by the higher median NIHSS scores of our 21 dropouts from the 6-month follow-up. As a sum score of the multiple gross neurological impairments, the NIHSS captures many of the obvious hinders of working life. In a cohort with frequent gross neurological impairments, a high NIHSS score would certainly offer a powerful estimate for the occupational outcome.
Our consecutive cohort is designed to be representative of working-aged patients with their first-ever stroke who had received a high standard acute stroke treatment. In our data, $61 \%$ of the patients leaving the acute care had an NIHSS score of 1 or 0 . The functional recovery of the cohort was good as well. Nevertheless, the patients' cognitive deficits were severe and frequent enough to explain the rather adverse return to work rate of $41 \%$. Even those dropouts with a higher median NIHSS scores had a deficit in psychomotor speed more frequently. Indeed, in many cases, the cognitive deficits seem to be the primary health-related determinant of the occupational outcome, and gross neurological impairments are insensitive to more fine-grained yet debilitating cognitive deficits. ${ }^{39}$

Other limitations of this study are the modest sample sizes for both the patients and controls and the fact that the control group was not equivalent in size to the patient group. The timing of the initial neuropsychological assessment was balanced to minimise the possible effect of changing acute conditions, such as cerebral oedema and intracerebral pressure. However, these factors were not explicitly controlled for. The patients' own conception of why they have not returned to work would help the interpretation of the results. Unfortunately, we were not able to fully answer this question. Finally, neuropsychological patient studies, including ours, would benefit from accurate data about the patients' premorbid cognitive state. The issue was addressed with a carefully collected control group, but it certainly does not solve the problem entirely. All these factors should be taken into account when evaluating the relevance of our results.

In conclusion, the prognostic benefits of early neuropsychological assessments completed within the first weeks after stroke are emphasised. In working-aged patients, the initial cognitive severity of stroke predicted the inability to return to work after a first-ever ischaemic stroke. The results were 
controlled for demographic, occupational and clinical factors as well as mood state. In addition to predicting the long-term cognitive and functional outcomes and quality of life, early neuropsychological assessments can serve in the prediction of returning to work.

Acknowledgements University Instructor Jari Lipsanen was consulted with regard to statistical methods.

Contributors TK conceptualised the study, undertook data collection, designed statistical analysis and analysed the data, and drafted and revised the draft paper. He is the guarantor. KT and SL undertook data collection and drafted and revised the manuscript. SM and PB undertook data collection and revised the manuscript. EP conceptualised the study, administrated the funding, and drafted and revised the manuscript.

Funding The Social Insurance Institution of Finland (KELA) and Lapland Hospital District EVO-fund funded this study.

Competing interests None.

Ethics approval Provided by the ethics committee of Helsinki University Central Hospital.

Provenance and peer review Not commissioned; externally peer reviewed.

\section{REFERENCES}

1. Brown DL, Boden-Albala B, Langa KM, et al. Projected costs of ischemic stroke in the United States. Neurology 2006;67:1390-5.

2. Treger I, Shames J, Giaquinto S, et al. Return to work in stroke patients. Disabil Rehabil 2007;29:1397-403

3. Daniel K, Wolfe CDA, Busch MA, et al. What are the social consequences of stroke for working-aged adults? A systematic review. Stroke 2009;40:e431-40.

4. Brott T, Adams HP Jr, Olinger CP, et al. Measurements of acute cerebral infarction: a clinical examination scale. Stroke 1989;20:864-70.

5. Neau J-P, Ingrand $\mathrm{P}$, Mouille-Brachet $\mathrm{C}$, et al. Functional recovery and social outcome after cerebral infarction in young adults. Cerebrovasc Dis 1998;8:296-302.

6. Mahoney FI, Barthel D. Functional evaluation: the Barthel Index. Md State Med J 1965;14:56-61.

7. Saeki S, Toyonaga T. Determinants of early return to work after stroke in Japan. $J$ Rehabil Med 2010:42:254-8.

8. Busch MA, Coshall C, Heuschmann PU, et al. Sociodemographic differences in return to work after stroke: the South London stroke Register (SLSR). J Neurol Neurosurg Psychiatry 2009;80:888-93.

9. Wozniak MA, Kittner SJ. Return to work after ischemic stroke: a methodologica review. Neuroepidemiology 2002;21:159-66.

10. Howard G, Till JS, Toole JF, et al. Factors influencing return to work following cerebral infarction. JAMA 1985;253:226-32.

11. Black-Schaffer RM, Osberg JS. Return to work after stroke: development of a predictive model. Arch Phys Med Rehabil 1990;71:285-90.

12. Hsich C-L, Lee M- H. Factors influencing vocational outcomes following stroke in Taiwan: a medical centre-based study. Scand J Rehabil Med 1997:29:113-20.

13. Lindstrom B. Positive attitudes and preserved high level of motor performance are important factors for return to work in younger persons after stroke: a national survey. J Rehabil Med 2009:41:714-18.

14. Kotila M, Waltimo 0 , Niemi M-L, et al. The Profile of recovery from stroke and factors influencing outcome. Stroke 1984;15:1039-44.
15. Nys GMS, van Zandvoort MJE, de Kort PLM, et al. The prognostic value of domainspecific cognitive abilities in acute first-ever stroke. Neurology 2005;64:821-7.

16. Barker-Collo S, Feigin V. The impact of neuropsychological deficits on functional stroke outcomes. Neuropsychol Rev 2006:16:53-64.

17. Feigin VL, Barker-Collo S, McNaughton H, et al. Long-term neuropsychological and functional outcomes in stroke survivors: current evidence and perspectives for new research. J Stroke 2008;3:33-40.

18. Hochstenbach JB, Anderson PG, van Limbeek J, et al. Is there a relation between neuropsychologic variables and quality of life after stroke? Arch Phys Med Rehabil 2001;82:1360-6

19. Nys GMS, van Zandvoort MJE, van der Worp HB, et al. Early cognitive impairment predicts long-term depressive symptoms and quality of life after stroke. J Neurol Sci 2006;247:149-56.

20. Tanaka H, Toyonaga $\mathrm{T}$, Hashimoto $\mathrm{H}$. Functional and occupational characteristics associated with very early return to work after stroke in Japan. Arch Phys Med Rehabil 2011;92:743-8.

21. Teasdale G, Jennett B. Assessment of coma and impaired consciousness A practical scale. Lancet 1974;304:81-4.

22. Adams HP Jr, Bendixen BH, Kappelle LJ, et al. Classification of subtype of acute ischemic stroke. Definitions for use in a multicenter clinical trial. TOAST. Trial of Org 10172 in acute stroke treatment. Stroke 1993;24:35-41.

23. Paciaroni M, Giancarlo A, Francesco C, et al. Early hemorrhagic transformation of brain infarction: rate, predictive factors, and influence on clinical outcome: results of a prospective multicenter study. Stroke 2008;39:2249-56.

24. Reitan RM. Validity of the trail making test as an indication of organic brain damage Perceptual Mot Skills 1958;8:271-6.

25. Poutiainen E, Kalska H, Laasonen M, et al, eds. Trail-Making-Testi. Käsikirja. (The Trail-Making Test A Finnish Manual). Helsinki: Psykologien Kustannus Oy, 2010.

26. Lezak MD, Howieson DB, Loring DW. Neuropsychological Assessment. 4th edn. New York: Oxford University Press, 2004.

27. Christensen AL. Luria's Neuropsychological Investigation Text. 2nd edn. Copenhagen: Munksgaard, 1979.

28. De Renzi E, Faglioni P. Normative data and screening power of a shortened version of the token test. Cortex 1978:14:41-9.

29. Wechsler D. WMS-R Käsikirja (The WMS-R. A Finnish Manual). Helsinki: Psykologien Kustannus Oy, 1996.

30. Benton AL. Revised Visual Retention Test. 4th edn. New York: Psychological Corporation, 1974

31. Wechsler D. WAIS-III Käsikirja. (The WAIS-III. A Finnish Manual). Helsinki: Psykologien Kustannus Oy, 2005.

32. Laine M, Niemi J, Koivuselkä-Sallinen P, et al. BDAT-Bostonin Diagnostinen Afasiatesti. (The Standardized Finnish Version of the Boston Diagnostic Aphasia Examination). Helsinki: Psykologien Kustannus Oy, 1997.

33. Carlesimo GA, Fadda L, Caltagirone C. Basic mechanisms of constructional apraxia in unilateral brain-damaged patients: role of visuo-perceptual and executive disorders. J Clin Exp Neuropsychol 1993;15:342-58.

34. Vilkki J. Hemi-inattention in visual search for parallel lines after focal cerebra lesions. J Clin Exp Neuropsychol 1989;11:319-31.

35. Ganguli M, Ratcliff G, Dekosky ST. Cognitive test scores in community-based older adults with and without dementia. Aging Ment Health 1997:1:176-80.

36. McNair DM, Lorr M. An analysis of mood in neurotics. J Abnorm Soc Psychol 1964;69:620-7.

37. Sheehan DV, Harnett-Sheehan K, Raj BA. The measurement of disability Clin Psychopharmacol 1996;11:89-95.

38. Gottesman RF, Hillis AE. Predictors and assessment of cognitive dysfunction resulting from ischaemic stroke. Lancet Neurol 2010;9:895-905.

39. Gottesman RF, Kleinman JT, Davis C, et al. The NIHSS-Plus: improving cognitive assessment with the NIHSS. Behav Neurol 2009/2010:22:11-15. 